\title{
EFFECTS OF POLISHING PROCEDURES ON COLOR STABILITY OF COMPOSITE RESINS
}

\author{
Ahmet Umut GÜLER ${ }^{1}$, Eda GÜLER ${ }^{2}$,Ali Çağin YÜCEL ${ }^{3}$, Ertan ERTAŞ $^{3}$
}

1- DDS, PhD, Associate Professor in Department of Prosthodontics, Faculty of Dentistry, Ondokuz Mayis University, Samsun, Turkey.

2- DDS, PhD, Assistant Professor in Department of Restorative Dentistry, Faculty of Dentistry, Ondokuz Mayis University, Samsun, Turkey.

3- DDS, PhD, Associate Professor in Department of Restorative Dentistry, Faculty of Dentistry, Ondokuz Mayis University, Samsun, Turkey.

Corresponding address: Dr. Eda Güler - Ondokuz Mayis University - Faculty of Dentistry - Department of Restorative Dentistry 55139 - Kurupelit Samsun - Turkey Fax: 0090-362 4576032 - e-mail: edaguler@omu.edu.tr

Received: June 18, 2008 - Accepted: September 12, 2008

\begin{abstract}
$T_{\text {he }}$

he purpose of this study was to investigate the effect of different polishing methods on color stability of posterior, universal and nanohybrid composite resin restorative materials upon exposure to a staining agent. Twenty-five specimens were prepared for each of 5 different composite resins (Filtek Z250, Filtek P60, Quadrant LC, Grandio and Filtek Supreme). Specimens were divided into 5 groups and different polishing procedures, including polishing discs (Pd), polishing discs then diamond polishing paste (PdP), polishing discs then a liquid polishing system (Biscover) (PdB), and combinations of these (PdPB) were used. Unpolished specimens served as the control (C). The specimens were stored for $48 \mathrm{~h}$ in a coffee solution. The color of all specimens was measured before and after exposure with a colorimeter, and total color change $\left(\Delta \mathrm{E}^{*}\right)$ were calculated. The data were analyzed with a two-way ANOVA and the means were compared by Tukey HSD test $(\alpha=0.05)$. The lowest color difference was observed in the groups PdP and C, while the highest color difference was observed in PdPB, and PdB. When comparing the five different restorative materials, no significant difference was observed between FiltekP60 and FiltekZ250, and these materials demonstrated significantly less color change than Quadrant LC and the nanohybrid materials (Grandio, Filtek Supreme). The posterior (Filtek P60) and universal (Filtek Z250) composite resin restorative materials, which do not contain tetraethyleneglycol dimethacrylate (TEGDMA), were found to be less stainable than the nanohybrid (Grandio, Filtek Supreme) and universal (Quadrant LC) composite resins, which contain TEGDMA. The use of diamond polishing paste after polishing with polishing discs significantly decreased staining when compared to the groups that used polishing discs alone, for all restorative materials tested. The highest color change values were obtained for the specimens that were polished with the Biscover liquid polish system (PdB and PdPB groups).
\end{abstract}

Key words: Color. Composite resins. Polishing. Staining.

\section{INTRODUCTION}

Increasing demand for esthetic dentistry has been coupled with a rapid rate of development of new restorative resin-based materials. Unesthetic teeth due to hypoplasia, fluorosis, fractures, caries, and shape, form or color irregularities can be treated with different approaches. These approaches include conservative, preventive and esthetic techniques such as bleaching, surface coating, esthetic contouring, composite restoration and porcelain or composite laminate veneering ${ }^{1}$.

A resin composite is composed of four major components: organic polymer matrix, inorganic filler particles, coupling agents, and the initiator-accelerator system. The organic polymer matrix in most commercial composites today is either an aromatic or urethane diacrylate oligomer. The three most common oligomers that have been used in dental composites are bisphenol A diglycidyl ether methacrylate (bis-GMA), urethane dimethacrilate (UDMA), and triethylene glycol dimethacrylate (TEGDMA). Composite resins are commercially classified as microfilled, packable, flowable, laboratory, core, provisional, and compomers ${ }^{23}$.

Proper finishing and polishing are important procedures that enhance both esthetics and longevity of restored teeth ${ }^{8,16}$. Restoration finish, surface roughness and surface integrity, as well as the physicochemical properties of the material itself, can influence plaque retention and staining of the composite resin $^{3}$. Staining or discoloration is one of the primary reasons for replacement of composite restorations ${ }^{20}$. Various finishing and polishing techniques have been examined with different types of composite resins in order to produce a smooth surface $5,13,26,27$.

Discoloration of tooth-colored, resin-based materials may be caused by intrinsic and extrinsic factors. The intrinsic factors involve the discoloration of the resin material itself, such as the alteration of the resin matrix and of the interface of matrix and fillers. Every component may contribute to this phenomenon. 
Extrinsic factors for discoloration include staining by adsorption or absorption of colorants as a result of contamination from exogenous sources ${ }^{14}$.

To our best knowledge no study has evaluated the effects of polishing techniques on color stability of posterior microhybrid and nanohybrid composite resins. The purpose of this study was to investigate the effect of different polishing methods on the color stability of different types of composite resin restorative materials upon exposure to a staining agent. The research hypothesis was that color stability of the composite resins is affected by the type of composite and the polishing procedures.

\section{MATERIAL AND METHODS}

Twenty-five cylindrical specimens $(15 \times 2 \mathrm{~mm})$ were prepared for each of five composite resin restorative materials (Table 1), which were widely used in Turkey using a brass mold. The materials were manipulated and polymerized according to the manufacturers' instructions. Light-polymerized specimens were polymerized using a halogen lamp (Astralis 3, Ivoclar-Vivadent, Schaan, Liechtenstein) with light intensity of $400 \mathrm{~mW} / \mathrm{cm}^{2}$ for $20 \mathrm{~s}$ and with the light tip approximately 1 $\mathrm{mm}$ away from the specimens for both sides. Both sides of the specimens were wet-ground with 1000-grit silicon carbide abrasive paper for $10 \mathrm{~s}$ on a $300 \mathrm{rpm}$ grinding machine (Buehler Metaserv, Buehler, Germany).

The five composite restorative material specimens were further divided into five groups of five specimens each, according to the different surface polishing procedures. Polishing and staining procedures were applied to both sides of the specimens. Group $\mathrm{C}$ specimens served as the control group with no polishing procedure applied. In the group Pd the specimens were polished with a series of polishing discs (SofLex; 3M/ESPE, St. Paul, MN, USA) with an electric handpiece (K10; Kavo, Leutkirch, Germany) at 15,000 rpm for $15 \mathrm{~s}$ for each disk (coarse, medium, fine, and superfine). In the group $\mathrm{Pd}-\mathrm{B}$ the specimens were polished with discs as in group Pd, and then a liquid polishing material including ethoxylated Bisphenol A diacrylate, urethaneacrylate ester and Polyethyleneglycol Diacrylate (Biscover; Bisco, Inc, Schaumburg, IL, USA) was applied on the specimens according to the manufacturer's recommendations. In the group Pd-P, specimens were polished with discs as in group $\mathrm{Pd}$, and then polished with a prophylactic cup mounted on the electric handpiece at 15,000 rpm using diamond polishing paste (Sparkle, Pulpdent, Watertown, MA, USA) for $15 \mathrm{~s}$. The group $\mathrm{Pd}-\mathrm{P}-\mathrm{B}$, specimens were polished as in group Pd-P, and then the liquid polish (Biscover) was applied as described for PdB. The specimens were then stored in distilled water at $37^{\circ} \mathrm{C}$ for $24 \mathrm{~h}$.

TABLE 1- Materials used in study

\begin{tabular}{|c|c|c|c|c|c|c|}
\hline Product & $\begin{array}{l}\text { Composite } \\
\text { Resin Type }\end{array}$ & Matrix & $\begin{array}{c}\text { Composition } \\
\text { Filler type }\end{array}$ & $\begin{array}{c}\text { Filler } \\
\text { weight (\%) }\end{array}$ & $\begin{array}{l}\text { Lot /Code } \\
\text { Number }\end{array}$ & Manufacturer \\
\hline Filtek P60 & Microfilled & $\begin{array}{l}\text { Bis-GMA, } \\
\text { UDMA, } \\
\text { Bis-EMA }\end{array}$ & $\begin{array}{c}\text { Zirconia/silica } \\
\text { (0.01 to } 3.5 \mu \mathrm{m})\end{array}$ & 80 & $4 U L / 4720 A 3$ & $\begin{array}{c}\text { 3M ESPE, Seefeld } \\
\text { Germany }\end{array}$ \\
\hline Filtek Z250 & Microfilled & $\begin{array}{l}\text { Bis-GMA, } \\
\text { UDMA, } \\
\text { Bis-EMA }\end{array}$ & $\begin{array}{c}\text { Zirconia/silica } \\
\text { (0.01 to } 3.5 \mu \mathrm{m})\end{array}$ & 78 & 4AE/6020A3 & $\begin{array}{c}\text { 3M/ESPE, St. Paul, } \\
\text { MN, USA }\end{array}$ \\
\hline Quadrant LC & Microfilled & $\begin{array}{l}\text { Bis-GMA, } \\
\text { TEGDMA }\end{array}$ & $\begin{array}{c}\text { Ba-Al-F Silica } \\
(0.02-2 \mu \mathrm{m}) \\
\mathrm{SiO}_{2} \\
(0.02-0.07 \mu \mathrm{m})\end{array}$ & 72 & S010111C & $\begin{array}{l}\text { Cavex, Haarlem, } \\
\text { Netherlands }\end{array}$ \\
\hline $\begin{array}{c}\text { Filtek } \\
\text { Supreme }\end{array}$ & Nanofilled & $\begin{array}{l}\text { Bis-GMA, } \\
\text { UDMA, } \\
\text { TEGDMA, } \\
\text { Bis-EMA }\end{array}$ & $\begin{array}{c}\text { Silica }(20 \mathrm{~nm}) \\
\text { Zirconia/silica }(20 \\
\mathrm{nm})\end{array}$ & 78.5 & 5BW/3910A3E & $\begin{array}{c}\text { 3M/ESPE, St. Paul, } \\
\text { MN, USA }\end{array}$ \\
\hline Grandio & Nanofilled & $\begin{array}{l}\text { Bis-GMA, } \\
\text { TEGDMA }\end{array}$ & $\begin{array}{l}\text { Glass-ceramic } \\
\text { (microfiller) } 1 \mu \mathrm{m} \text {, } \\
\mathrm{SiO}_{2} \text { (nanofiller) } \\
20-60 \mathrm{~nm} .\end{array}$ & 87 & 581079 & $\begin{array}{c}\text { Voco, Cuxhaven, } \\
\text { Germany }\end{array}$ \\
\hline
\end{tabular}


TABLE 2- Two-way analysis of variance for composite resin restorative materials and surface finishing procedures

\begin{tabular}{lrrrrr}
\hline Variable (Source) & df & Sum of squares & Mean squares & F value & Probability $^{*}$ \\
\hline Finishing Procedures & 4 & 873.305 & 218.326 & 982.462 & .0001 \\
Material & 4 & 12.680 & 3.170 & 14.265 & .0001 \\
Interaction & 16 & 5.392 & .337 & 1.516 & .109 \\
Error & 100 & 22.222 & .222 & & \\
\hline
\end{tabular}

*Significantly different at $p<0.05$.

TABLE 3- Mean values (standard deviation) of total color change $(\Delta \mathrm{E})$ of the composite resin restorative materials according to the evaluated groups

\begin{tabular}{|c|c|c|c|c|c|}
\hline \multirow[t]{2}{*}{ Groups } & \multicolumn{5}{|c|}{ Composite Resins } \\
\hline & Filtek P60 & Filtek Z250 & Quadrant LC & Grandio & Filtek Supreme \\
\hline $\mathrm{PdP}$ & $2.8(0.4)$ & $3.0(0.3)$ & $3.4(0.3)$ & $3.3(0.6)$ & $3.9(0.4)$ \\
\hline C & $3.3(0.5)$ & $3.3(0.4)$ & $3.5(0.2)$ & $3.9(0.3)$ & $4.3(0.4)$ \\
\hline $\mathrm{Pd}$ & $4.4(0.4)$ & $4.7(0.4)$ & $4.7(0.5)$ & $5.1(0.4)$ & $5.6(0.5)$ \\
\hline PdPB & $8.7(0.7)$ & $8.6(0.5)$ & $9.4(0.5)$ & $9.1(0.6)$ & $9.0(0.4)$ \\
\hline $\mathrm{PdB}$ & $9.1(0.5)$ & $9.0(0.6)$ & $10.1(0.5)$ & $9.7(0.4)$ & $9.5(0.7)$ \\
\hline
\end{tabular}

Vertical and horizontal lines connect groups that are not significantly different at $p>0.05$

$\mathrm{PdP}$ - polishing discs then diamond polishing paste; $\mathrm{C}$ - control; $\mathrm{Pd}$ - polishing discs; $\mathrm{PdB}$ - polishing discs then a liquid polishing system (Biscover); PdPB- a combinations of these methods.

Baseline color measurement of all specimens was recorded before exposure to the staining agent with a colorimeter (Minolta CR-300; Minolta Co, Osaka, Japan) using CIE (Commission Internationale de l'Eclairage) ${ }^{15} \mathrm{~L}^{*} \mathrm{a}^{*} \mathrm{~b}^{*}$ relative to standard illuminant A against a white background. $\mathrm{L}^{*}$ refers to the lightness coordinate, and with value ranges from zero (black) to 100 (white). The values, $\mathrm{a}^{*}$ and $\mathrm{b}^{*}$ are chromaticity coordinates in the red-green axis and the yellow-blue axis, respectively. Positive $\mathrm{a}^{*}$ values indicate a shift to red, and negative values indicate a shift to green. Similarly, positive $b^{*}$ values indicate the yellow color range, and negative values indicate the blue color range. Measurements were repeated 3 times for each specimen and the mean values of the $L^{*}, a^{*}$, and $\mathrm{b}^{*}$ data were calculated. After baseline color measurements were made, all specimens were stored in $100 \mathrm{~mL}$ of coffee (Nescafe Classic; Nestlé Suisse SA, Vevey, Switzerland) at $37^{\circ} \mathrm{C}$ for 48 h. The coffee ( $3.6 \mathrm{~g}$ ) was dissolved in $300 \mathrm{~mL}$ of boiling distilled water according to manufacturer's recommendation. After 10 min of stirring, the solution was filtered through a filter paper. The storage period of $48 \mathrm{~h}$ was selected as the coffee manufacturer states that the average time for consumption of one cup of a drink is $15 \mathrm{~min}$, and among coffee drinkers, the average consumption of coffee is 3.2 cups per day. Therefore, the 48 -h storage time simulated consumption of the drink over a two-month period.

After $48 \mathrm{~h}$ in the coffee solution, the specimens were rinsed with distilled water for $5 \mathrm{~min}$ and blotted dry with tissue paper before color measurement. At this point, color readings were made using the colorimeter in the same manner described for baseline readings. The calculation of the color variation $\Delta \mathrm{E}^{*}$ between the two color measurements (after 48 hour storage and baseline) in the $3-\mathrm{d} \mathrm{L}^{*} \mathrm{a}^{*} \mathrm{~b}^{*}$ color space was done using the following equation ${ }^{18,34}$ :

$\Delta \mathrm{E}^{*}=\left[\left(\mathrm{L}_{1}{ }^{*}-\mathrm{L}_{0}{ }^{*}\right)^{2}+\left(\mathrm{a}_{1}{ }^{*}-\mathrm{a}_{0}{ }^{*}\right)^{2}+\left(\mathrm{b}_{1}{ }^{*}-\mathrm{b}_{0}{ }^{*}\right)^{2}\right]^{1 / 2}$

Two-way ANOVA using statistical software (SPSS for Windows, Version 12.0.1; SPSS Inc, Chicago, IL, USA) was used to evaluate the effect of material type and surface finishing procedure on color change, including the possibility of interactions between the two factors. The means were then compared by Tukey HSD test $(\alpha=0.05)$.

\section{RESULTS}

According to the ANOVA results, although restorative materials and surface polishing procedures were significant $(\mathrm{p}=0.0001)$, interaction between materials and surface procedures were not significant $(\mathrm{p}=0.109)$ (Table 2$)$.

Means and standard deviations of color changes and group differences of the posterior composite resins tested are listed in Table 3. For the restorative materials tested, the lowest color difference was observed for the groups PdP and C. Color differences of the Group Pd demonstrated average values of color differences according to the arrangement for groups. The 
greatest color difference for the composite resin restorative materials tested was observed for the groups PdPB and PdB. When comparing the five different restorative materials, no significant difference was observed between Filtek P60, and Filtek Z250 material groups ( $>0.05)$ and these groups demonstrated significantly $(p<0.0001)$ less color change than the nanohybrid (Grandio, Filtek Supreme) and universal composite resin (Quadrant LC) groups, which were not significantly $(\mathrm{p}>0.05)$ different from one another (Table 3$)$.

\section{DISCUSSION}

On the basis of these data, the hypotheses set as the premise of this study should be accepted. Color stability of the composite resin materials is related to type of the composite resin restorative materials, and polishing procedures. Discoloration can be evaluated with various instruments. Since instrument measurements eliminate the subjective interpretation of visualcolor comparison, spectrophotometers and colorimeters have been used to measure color change in dental materials ${ }^{9,10,11,21,28,29}$. The CIE Lab system for measuring chromacity was chosen to record color differences because it is well suited for determination of small color differences ${ }^{19,21}$. The use of the CIE Lab system is also commonly used in dentistry because $\mathrm{L}^{*}, \mathrm{a}^{*}$, and $b^{*}$ are evenly distributed in a perceptual color space.

Discoloration of tooth-colored, resin-based materials may be caused by intrinsic and extrinsic factors. The intrinsic factors involve the discoloration of the resin material itself, such as the alteration of the resin matrix and of the interface of matrix and fillers. Every component may contribute to this phenomenon. Extrinsic factors for discoloration include staining by adsorption or absorption of colorants as a result of contamination from exogenous sources ${ }^{14,22}$. The staining of polymeric materials by colored solutions, coffee and tea, nicotine and beverages has been reported ${ }^{7,10,24,28,33}$. In this study, coffee was used as a colorant agent because of its frequent consumption in daily life. Before the baseline color measurement, specimens were stored in distilled water at $37^{\circ} \mathrm{C}$ for $24 \mathrm{~h}$. The rehydration simulated the first day of service for restorations in the oral environment. It is known that the type of materials used in this study imbibe most of the water during the first day of immersion ${ }^{2}$.

Staining of composite resin surface is a complex phenomenon that can involve several mechanisms ${ }^{32}$. Finishing and polishing procedures may influence surface smoothness, which is related to early discoloration and rough surfaces mechanically retain surface stains more than smooth surfaces ${ }^{12,31}$. Manufacturers provide a variety of instruments to accomplish finishing and polishing, such as diamond rotary cutting instruments, carbide burs, abrasive-impregnated rubber cups and points, abrasive discs, and polishing pastes. Studies on the polishing of resin-based materials have reported that dedicated polishing systems and procedures should be used to polish $5,11,26,27,30,31$.

Color change values equal or larger than 3.7 were considered visually perceptible as well as clinically unacceptable ${ }^{17}$. According to Heymann, et al. ${ }^{13}$, polishing discs are suitable for contouring and polishing composite restorations. However, according to the results of a previous study ${ }^{11}$, restorative materials that were polished with polishing discs demonstrated the highest color change values for materials tested. The same result was found in the present study.

Sen, et al. ${ }^{30}$ reported that the polishing pastes provided a smoother surface effectively and stated that diamond polishing pastes produced smoother surfaces rather than aluminum oxide pastes in bis-acryl composite group. Güler, et al. ${ }^{11}$ reported that the groups in which the diamond paste was used were more color stable than the others, which is in concordance with the results from the present study.

Biscover is a light-cured resin system with a low amount of filler particles. Although the manufacturer of the Biscover states that a smooth polished surface without a sticky air-inhibited layer and a high luster finish for composite resins can be obtained with a liquid polishing system, the present study indicated that the use of this polish system seemed to increase the staining of the specimens. Rough surfaces may be discolored by adsorption of stains, although there is not always a relationship between surface roughness and staining ${ }^{32}$. It is well known that the use of matrix strips will produce the smoothest composite surface because of the resin rich layer at the surface ${ }^{25}$. However, Bayne and Taylor ${ }^{1}$ stated that increasing the filler contents of composite resins generally improve the physical, chemical and mechanical properties such as water absorption, color stability and wear resistance. This type of resin-rich layer might occur also after the application of the liquid polishing system and may be responsible for the relatively high discoloration when compared to the other polishing methods in this study.

Staining is directly related to the resin phase of composites ${ }^{25}$. Urethane dimethacrylate (UDMA) seems to be more stain resistant than bis-GMA ${ }^{19}$. The resin systems of Quadrant LC, Grandio, and Filtek Supreme consist of three primary components; bis-GMA, UDMA, and TEGDMA. However, the resin system of Filtek Z250, and Filtek P60 consist primarily of; bis-GMA, UDMA, and bis-EMA. In these restorative systems, the majority of TEGDMA, a somewhat hydrophilic monomer, has been replaced with a blend of UDMA and bisEMA $^{4}$. According to the manufacturers, Filtek Z250 and Filtek P60 composite resins impart a greater hydrophobicity to the composite resin. The low staining susceptibility of Z250 and P60 may be related to a low water sorption rate due to the use of hydrophobic resins ${ }^{6}$.

The present study has several limitations. The specimen surfaces were flat, whereas, clinically, composite resin restorations have an irregular shape with convex and concave surfaces. Furthermore, the application of surface finishing procedures tested in this study may be difficult to perform clinically. However, there is limited published information as to how storage conditions reflect the clinical situation. The solution used in this study does not consider all substances to which composite restorative materials may be exposed. Other factors that could influence the degree of total color change include thermal cycling, aging and abrasion. In addition, effects of polishing techniques on the surface roughness and their relation to the stain ability or color change on composite resin 
materials have not been clarified and should be considered for future study.

\section{CONCLUSIONS}

Within the limitations of this study, the following conclusions were drawn: 1. The posterior (Filtek P60) and universal (Filtek Z250) composite resin restorative materials, which do not contain TEGDMA, were more color stable than the nanohybrid composite resins (Grandio, Filtek Supreme) and a universal composite resin (Quadrant LC) containing TEGDMA; 2. The use of diamond polishing paste after the use of polishing discs significantly decreased staining when compared to the use of polishing discs alone, for all tested restorative materials; 3 The highest color change values were obtained for the specimens that were polished with the Biscover liquid polish system ( $\mathrm{PdB}$ and $\mathrm{PdPB}$ groups). These $\Delta \mathrm{E}$ values were significantly higher when compared to the $\Delta \mathrm{E}$ values of the other groups.

\section{REFERENCES}

1- Bayne SC, Taylor DF. Dental materials. In: Sturdevant CM (Ed.). The art and science of operative dentistry. 3rd. ed. St. Louis: Mosby; 1995. p. 20687.

2- Benington IC, Cunningham JL. Sorption determination of hollow VLC resin obturators. J Dent. 1991;19:124-6.

3- Bollen CML, Lambrechts P, Quirynen M. Comparison of surface roughness of oral hard materials to the threshold surface roughness for bacterial plaque retention: a review of the literature. Dent Mater. 1997;13:258-69.

4- Choi KK, Ferracane JL, Hilton TJ, Charlton D. Properties of packable composites. J Esthet Dent. 2000;12:216-26.

5- Chung K. Effects of finishing and polishing procedures on the surface texture of resin composites. Dent Mater. 1994;10:325-30.

6- Douglas WH, Craig RG. Resistance to extrinsic stains by hydrophobic composite resin systems. J Dent Res. 1982;61:41-3.

7- Ertas E, Guler AU, Yucel AC, Köprülü H, Guler E. Color stability of resin composites after immersed in different drinks. Dent Mater J. 2006;25:371-6.

8- Goldstein RE. Finishing of composites and laminates. Clin North Am. 1989;33:305-18.

9- Gross MD, Moser JB. A colorimetric study of coffee and tea staining of four composite resins. J Oral Rehabil. 1977;4:311-22.

10- Güler AU, Kurt S, Kulunk T. Effects of various finishing procedures on the staining of provisional restorative materials. J Prosthet Dent. 2005;93:4538 .

11- Güler AU, Yilmaz F, Kulunk T, Güler E, Kurt S. Effects of different drinks on stainability of resin composite provisional restorative materials. J Prosthet Dent. 2005;94:118-24.

12- Hachiya Y, Iwaku M, Hosoda H, Fusayama T. Relation of finish to discoloration of composite resins. J Prosthet Dent. 1984;52:811-4.

13- Heymann HO, Sockwell CL, Haywood VB. Additional conservative esthetic procedures. In: Sturdevant CM, editor. The art and science of operative dentistry. 3rd ed. St. Louis: Mosby; 1995. p. 627-87.
14- Iazetti G, Burgess JO, Gardiner D, Ripps A. Color stability of fluoride containing restorative materials. Oper Dent. 2000;25:520-5.

15- International Commission on Illumination. Colorimetry: official recommendations of the international commission on illumination. 2nd ed. Vienna: Bureau Central de la CIE; 1986

16- Jefferies SR. The art and science of abrasive finishing and polishing in restorative dentistry. Dent Clin North Am. 1998;42:613-27.

17- Johnston WM, Kao EC. Assessment of appearance match by visual observation and clinical colorimetry. J Dent Res. 1989;68:819-22.

18- Judd DB, Wyszecki G. Color in business, science and industry. New York: Wiley;1975. p. 5-90.

19- Khokhar ZA, Razzoog ME, Yaman P. Color stability of restorative resins. Quintessence Int. 1991;22:733-7.

20- Kroeze HJP, Plasschert AJ, Van't Hof MA, Truin GJ. Prevalence and need for replacement of amalgam and composite restorations in Dutch adults. J Dent Res. 1990;69:1270-4.

21- Okubo SR, Kanawati A, Richards MW, Childress S. Evaluation of visual and instrument shade matching. J Prosthet Dent. 1998;80:642-8.

22- Paravina RD, Powers JM. Esthetic color training in dentistry. St. Louis: Mosby; 2004. p. 69-123.

23- Powers JM, Sakaguchi RL. Craig's restorative dental materials. $12^{\text {th }}$ ed. St. Louis: Mosby; 2006. p. 189-212.

24- Raptis CN, Powers JM, Fan PL, Yu R. Staining of composite resins by cigarette smoke. J Oral Rehabil. 1982;9:367-71.

25- Reis AF, Giannini M, Lovadino JR, Ambrosano GM. Effects of various finishing systems on the surface roughness and staining susceptibility of packable composite resins. Dent Mater. 2003;19:12-8.

26- Reis AF, Giannini M, Lovadino JR, Santos Dias CT dos. The effect of six polishing systems on the surface roughness of two packable composite resins. Am J Dent. 2002;15:193-7.

27- Roeder LB, Tate WH, Powers JM. Effect of finishing and polishing procedures on the surface roughness of packable composites. Oper Dent. $2000 ; 25: 534-43$

28- Satou N, Khan AM, Matsumae I, Sata J, Shintani H. In vitro color change of composite-based resins. Dent Mater. 1989;5:384-7.

29- Seghi RR, Gritz MD, Kim J. Colorimetric changes in composites resulting from visible-light-initiated polymerization. Dent Mater. 1990;6:133-7.

30- Sen D, Goller G, Issever H. The effect of two polishing pastes on the surface roughness of bis-acryl composite and methacrylate-based resins. J Prosthet Dent. 2002;88:527-32.

31- Shintani H, Satou J, Satou N, Hayashihara H, Inoue T. Effects of various finishing methods on staining and accumulation of Streptococcus mutans HS-6 on composite resins. Dent Mater. 1985;1:225-7.

32- Smales RJ, Gerke DC. Clinical evaluation of light-cured anterior resin composites over periods of up to 4 years. Am J Dent. 1992;5:208-11.

33- Um CM, Ruyter IE. Staining of resin-based veneering materials with coffee and tea. Quintessence Int. 1991;22:377-86.

34- Wyszechi G, Stiles WS. Color science: concepts and methods, quantitative data and formulas. 2nd ed. New York: John Wiley; 1982. p.13-116. 